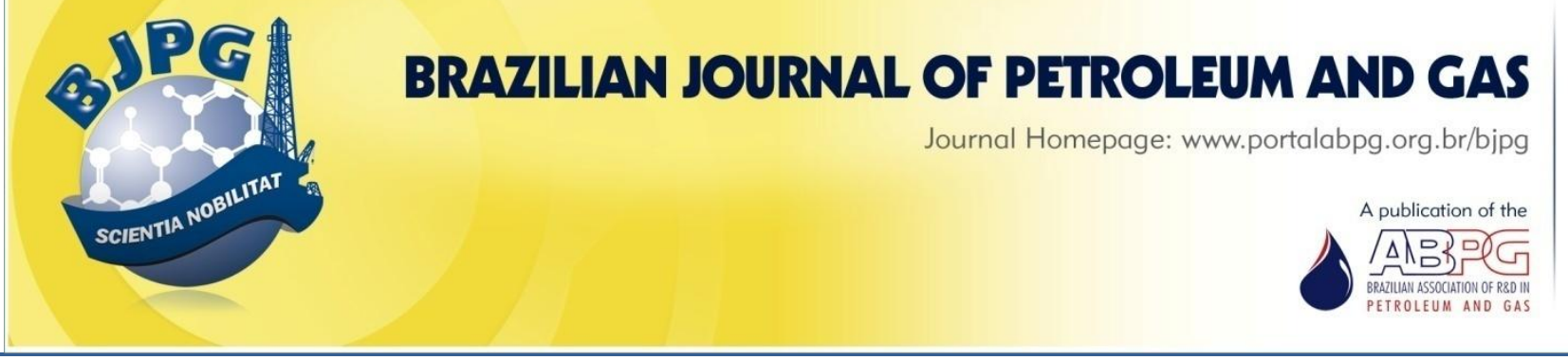

\title{
FLOW PARAMETER EVALUATION DURING THE OCCURRENCE OF A GAS KICK IN A PETROLEUM DRILLING USING TURBULENCE MODELS: A NUMERICAL STUDY
}

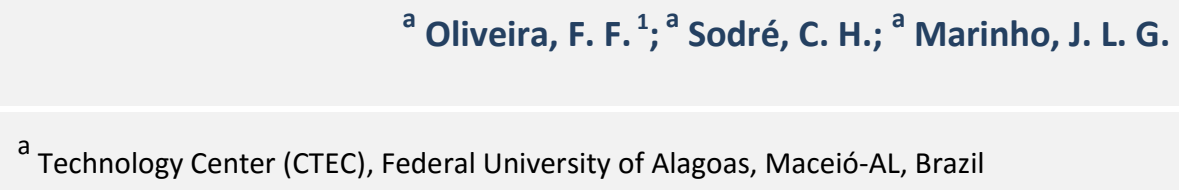

\begin{abstract}
The drilling of petroleum wells demand large investments and the use of highly skilled personnel in the operation to be viable economically. In extreme situations, drilling requires strict process control. One of the most important tasks in this process is controlling the pressure within the well to avoid the influx of formation fluids into the well, i.e. a kick. A kick consists of an unwanted formation fluid flow due to a pressure difference in the pit. To better understand this process, a simplified kick simulator using the ANSYS CFX software was developed and implemented to analyze the behavior of some variables inside the pit during the occurrence of a gas kick. In this model, the behavior of dynamic variables such as mud volume fraction, densities, and pressure of fluids inside the tube is evaluated during drilling using two types of drilling fluids and testing four different turbulence models: k-epsilon, RNG- k-epsilon, k-omega and SST. In these tests one can note that for both fluids analyzed, when using the SST model, there was a more rapid invasion of the gas. However, using the RNG k-epsilon model, a greater resistance to invasion was observed, and both fluids exhibited similar behavior when using the same turbulence model. One can also observe that the SST allows a greater pressure drop along the stretch of the well examined in the final moment of the simulation, while the RNG k-epsilon model is one that showed a lower pressure drop.
\end{abstract}

\section{KEYWORDS}

drilling fluids; kick; turbulence model; CFX

\footnotetext{
${ }^{1}$ To whom all correspondence should be addressed. Address: Universidade Federal de Alagoas, Centro de Tecnologia, Av. Lourival Melo Mota, Cidade Universitária, Maceio - AL Brazil. ZIP Code: 57000-000 | Phone: +55 (82) 3214-1260 |e-mail: ffreireoliveira@gmail.com doi:10.5419/bjpg2016-0012
} 


\section{INTRODUCTION}

During the process of drilling a well, a drilling fluid is pumped into the drill pipe and it returns through the annular region between the column and the wall of the well. Some drilling fluid purposes are: to carry to the surface the gravels generated from the drilling process; to stabilize the walls of the well; and to keep pressure gradient along the length of the well, among others (Nygaard and Nævdal, 2006).

One of the most important points in the drilling process is the pressure control into the well. If this control fails, it may occur an influx of formation fluids into the well, producing a kick. The kick is an abrupt discharge of oil, gas, or brine, or a combination of them, into the atmosphere from a drilling of a well (Nygaard and Nævdal, 2006; Ajienka and Owolabi, 1991).

Avelar (2008), Grace (2003), and Ajienka and Owolabi (1991) reported that some of the major causes of well kicks are: difference between the lower drilling fluid pressure and pore pressure of the formation; loss of circulation; and mud cut by gas, water, or oil.

With the advance of technology, the petrochemical industry has invested in softwares that simulate fluid dynamics behavior. High performance computers are capable of running these softwares and registering the dynamic behavior of the event, like a kick, which can be studied and the probability of the occurrence of a blowout can be reduced. Reducing the probability of a blowout avoids possible human and financial losses as well as environmental damage.

There are some numerical studies in the literature that aim to study the occurrence of kicks. Nunes (2002) developed a mathematical model to simulate a gas kick and provide the pressure variation in the choke line and in the annular space of the well during a well control situation in deep waters. Some considerations were implemented in the model: the effect of the well geometry, friction pressure losses, and the expansion of inflow. The author studied some parameters in well control, such as pit gain, water depth, diameter of the choke line, density, and rheological parameters of the drilling fluid, as well as the flow pumping in circulation.
Avelar (2008) implemented a kick simulator based on a mathematical model that solves a set of conservation partial differential equations for the two-phase flow with some auxiliary relationship, using the finite difference method. The goal of the simulation was to analyze the behavior of the drilling fluid, the gas in the surface, the pressures downhole, in casing shoe and in the surface, all with time.

Limoeiro (2011) developed a mathematical model to predict the behavior of the pressure in the well bottom's annular space and in the casing shoe when a gas kick is happening. The author implemented in the model some considerations regarding the effects of the well's geometry, frictional pressure drop, and two-phase flow models.

In general, a kick causes high pressure in the annular region due to the lower density of the gas. The gas expands when it reaches the surface, generating instability in the flow pattern of the drilling fluid due to turbulence generated in the mixture of drilling fluid and gas kick.

Turbulent flow is characterized when the particles are mixed in a nonlinear manner, chaotically, with swirls and turbulence as opposed to laminar flow.

It is a complex process, mainly because it is tridimensional, unsteady, involves many features, and adds significant effects on flow characteristics.

In most cases, the Navier-Stokes equations can describe both laminar and turbulent flows without the need for any additional information. However, turbulent flows at realistic Reynolds numbers span a large range of turbulent length and time scales. These scales can be much smaller than the smallest finite volume mesh, which can be practical in a numerical analysis (ANSYS, 2010).

Turbulence models were used to predict the effects of turbulence without having to solve only the Navier -Stokes equations, as in DNS (Direct Numerical Simulation), with extremely refined meshes that prevent the flow simulation due to the required computational effort and time (Klein, 2007).

Turbulence models are necessary because one cannot capture every scale of motion with the 
available technology directly. Also, there are unsteady (turbulent) motions affecting the flow that cannot be resolved directly. These motions, therefore, must be modeled. The turbulence model used, in some cases, can have a huge effect on the results obtained from CFD, due to the fact that all models have their limitations and no model is adequate for every situation (Nelson, 2014).

The more traditional turbulence models are those based on the proposition correlations for components of the Reynolds tensor. In these models, emergence comes from the decomposition of its average velocity component (given by applying the appropriate time average in a given time interval) and its fluctuating component or turbulent, proposing solutions to the closure problem.

The classical models can be classified into four groups: algebraic models, models to an equation, two equations models, and models of Reynolds stresses (Klein, 2007).

\subsection{Algebraic models}

Also known as Zero Equation Models, these models are based in the Boussinesq hypothesis that establishes the concept of turbulent viscosity. In these models, an algebraic equation, usually empirical, is used to determine the value of the turbulent viscosity. This model can be called zero equation model because it does not show any additional transport equation, only algebraic equations (Klein, 2007).

\subsection{0ne equation turbulence models}

In those models, which also employ the concept of eddy viscosity, a transport differential equation is solved for a given turbulent property, normally the turbulent kinetic energy, k. A second turbulent property, typically a turbulent length scale, is expressed by an algebraic equation (Klein, 2007).

\subsection{Two-equation turbulence models}

These turbulence models are used widely, as they offer a good compromise between numerical effort and computation accuracy. They are more sophisticated than the other models. Both the velocity and length scale are solved using separated transport equations (hence the term "two-equation") (ANSYS, 2010).
The two-equation models, which are also based on the concept of turbulent viscosity, have two transport differential equations of turbulent properties, configured as models of complete closure. These turbulent properties are independent quantities that are directly related to the length scales and turbulent time. Typically, these properties are the turbulent kinetic energy, $k$, and the dissipation rate of turbulent kinetic energy per mass unit, $\varepsilon$. Nevertheless, there are models that use, for example, the turbulent frequency, $\omega$, instead of the dissipation rate, $\varepsilon$ (Klein, 2007).

The k-epsilon and k-omega models use the gradient diffusion hypothesis to relate the Reynolds stresses to the mean velocity gradients and the turbulent viscosity. This is later modeled as the product of a scale of the turbulent velocity and turbulent length.

In two-equation models, the velocity scale of turbulence is calculated from the turbulent kinetic energy, which is supplied from the solution of the transport equation. The turbulent length scale is estimated from two properties of the turbulence field, usually turbulent kinetic energy and its dissipation rate. The dissipation rate of turbulent kinetic energy is supplied from the solution of its transport equation (ANSYS, 2010).

\subsection{Models of Reynolds stresses}

These models are based on transport equations for all components of the Reynolds stress tensor and the dissipation rate. The eddy viscosity hypothesis is not used in these models, instead, it solves an equation for the transport of Reynolds stresses in the fluid. The transport equations are solved for the individual stress components.

The exact production term and inherent modeling of stress anisotropies theoretically make these models more suited to complex flow; however, practice shows that they are often not superior to two-equation models (ANSYS, 2010).

The objective of the present work is to help understand what happens in the bottomhole of petroleum wells during the drilling process, to evaluate different turbulence models, and to offer a tool that can be used to predict the best behavior of some important variables like pressure and amount of formation fluid that can invade the pit. 


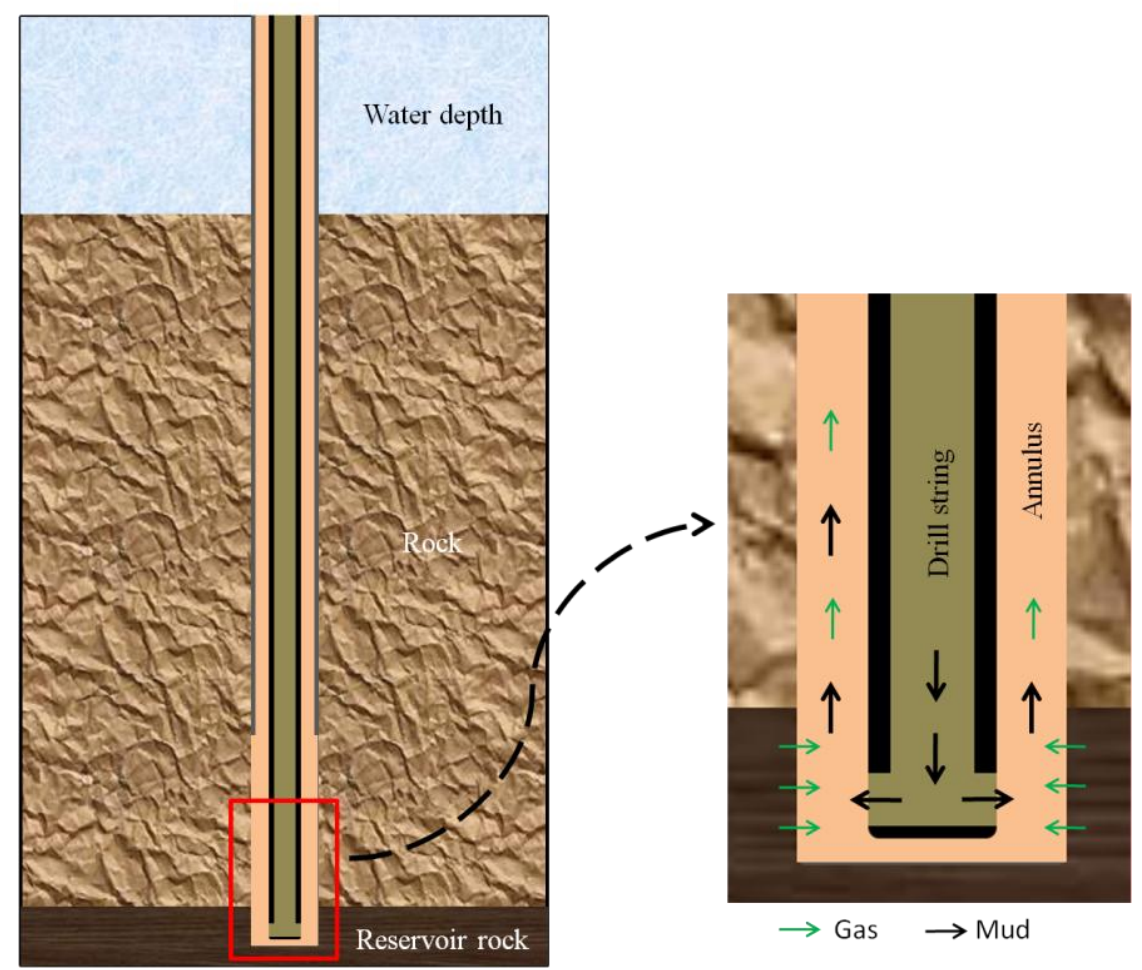

Figure 1. Representation of the well and detail of the final stretch.

\section{METHODOLOGY}

\subsection{Physical problem description (case studied)}

The case was studied to analyze the kick during drilling of the oil well. Figure 1 shows the sketch of an oil well being drilled. For the simulation of the kick, the gas inlet is located at the end of the stretch, without casing, of an oil well (drilled in reservoir rock). The fluid (black arrows in the detail of Figure 1), along with the gas (green arrows, in the detail of Figure 1), flows in the annular region in a two-phase flow upward. The study was performed by analyzing transient two-phase flow profiles.

\subsection{Geometric description of the studied domain}

The well studied is in the middle of the reservoir and it was assumed that the gas is distributed equally at the entrance. Considering the symmetry of the well, only a slice of the tube was taken to perform the simulation and state that what happens in this slice represents approximately what occurs in the whole region. This was done to simplify the domain to be studied and, especially, to reduce computational effort. A section of 45 degrees of the tube was modeled and it was assumed by symmetry, that the result obtained in this region can be extrapolated to entire area. The section is shown in Figures $2 \mathrm{~A}$ and $\mathrm{B}$.

It is also known that an oil well, especially in the pre-Salt region, frequently reaches depths exceeding five thousand meters in the final phase of drilling. So, to make a model span of such length would be impractical due to the computational effort required. Tests were performed to define the length of the stretch of the desired pipe. These tests consisted of previous simulations to observe how fast the equilibrium would be reached and to define the appropriate time step and the length of the pipe. Thus, after these tests, it was concluded that a tube of about 20 meters long would be suitable to represent what would happen in the pit at the time of the studied phenomenon.

After making the above considerations, the geometry was designed using the ANSYS ICEM 13.0 CFD software, as shown in Figure 2. The dimensions of the geometry are given in Table 1 and Figure $2 \mathrm{C}$. The mesh used was a structured 

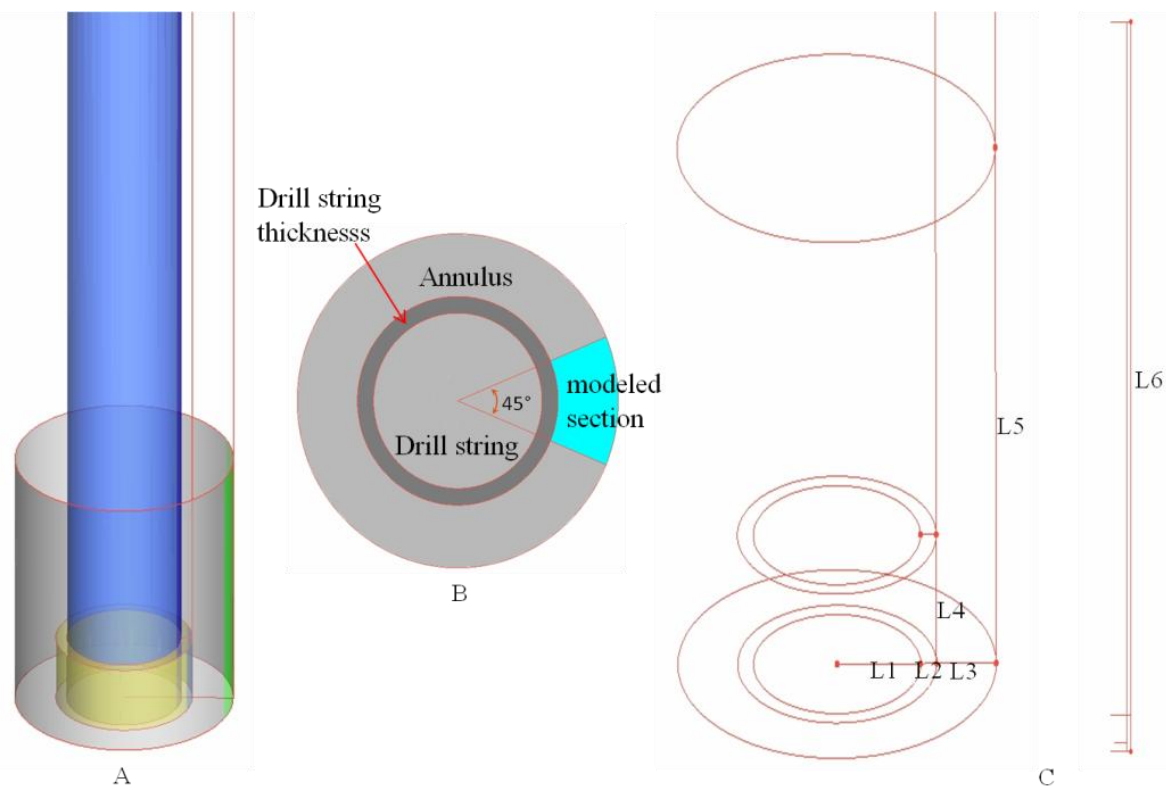

Figure 2. Dimensions of the geometry used in the model: $(A)$ three-dimensional representation; (B) Detail of the modeled section; and (C) size.

model with 237476 elements, predominantly hexahedral. Meshes with about one hundred thousand and about a half million elements were also tested. In the first case, the mesh refinement was insufficient to analyze the details of the fluid behavior inside the tube. In the second case, the results were very similar to those obtained using the chosen mesh, not justifying the extra refinement and consequent extra computational time (Oliveira et al., 2016).

\subsection{Drilling fluids and natural gas used}

Two non-Newtonian fluids were used as drilling fluid to perform the tests: A Power Law fluid (pseudoplastic) and a Bingham fluid. The parameters of each fluid are shown in Table 2.

Table 1. Features of developed geometry.

\begin{tabular}{cccl}
\hline Dimension & Value (in) & Value $(\mathbf{c m})$ & \multicolumn{1}{c}{ Description } \\
\hline $\mathrm{L} 1=\mathrm{d}_{\mathrm{i}} / 2$ & 2.1 & 5.334 & Inner radius of drill string \\
$\mathrm{L} 2$ & 0.4 & 1.016 & Drill string thickness \\
$\mathrm{L} 3$ & 1.5 & 3.81 & Annular thickness \\
$\mathrm{L} 4$ & 2.5 & 6.35 & Drilling fluid inlet height \\
$\mathrm{L} 5=\mathrm{H}_{\text {res }}$ & 10 & 25.4 & Gas inlet height \\
$\mathrm{L} 6$ & 800 & 2032 & Total height of the analyzed domain \\
\hline
\end{tabular}

Source: Avelar (2008); Author.

Table 2. Rheological properties of drilling fluids.

\begin{tabular}{lcccc}
\hline & \multicolumn{2}{c}{ Power Law } & \multicolumn{2}{c}{ Bingham } \\
Parameters & $\mathrm{K}\left({\left.\mathrm{Pa} . \mathrm{s}^{\mathrm{n}}\right)}\right.$ & $\mathrm{n}$ & $\tau_{\mathrm{L}}(\mathrm{Pa})$ & $\boldsymbol{\mu}_{\mathrm{p}}(\mathrm{Pa} . \mathrm{s})$ \\
Values & 2.4 & 0.376 & 3.527 & 0.019 \\
\hline
\end{tabular}

Source: Martins et al. (2012). 
Table 3. Methane gas properties.

\begin{tabular}{ll}
\hline Properties & Value \\
\hline Molar mass & $0.016 \mathrm{~kg} / \mathrm{mol}$ \\
Density & $223.7 \mathrm{~kg} / \mathrm{m}^{3}$ \\
Dynamic viscosity & $2.8242 \times 10^{-5} \mathrm{~Pa} . \mathrm{s}$ \\
Reference temperature & $365 \mathrm{~K}$ \\
Reference pressure & $4.997710^{7} \mathrm{~Pa}$ \\
\hline
\end{tabular}

Source: Peace (2013); Lee et al. (1966).

The natural gas found during drilling may show values above $90 \%$ methane in its composition (Lee et al., 1966). Thus, in this study, to simplify the modeling, it was considered that the composition of natural gas consisted only of methane. The main properties of this gas are shown in Table 3.

\subsection{Modeling considerations}

The following considerations were made with regard to the properties of the fluids involved:

- Both drilling fluids are considered incompressible;

- The variation of the gas compressibility was considered very small, and, therefore, neglected;

- The temperature variation in the evaluated stretch was neglected, i.e., in the stretch the temperature was assumed equal to the bottomhole temperature;

- The physicochemical properties of drilling fluids and gas remained constant in the analyzed section;

- The pumping drilling fluid and gas inlet speeds were considered constant in the analyzed time interval.

\subsection{Mathematical modeling}

The main governing equations, which represent the models, are given by the Equations below:

\subsubsection{The k-epsilon model in ANSYS CFX}

In this model, $k$ is the turbulence energy and defined as the variance of the fluctuations in velocity. $\varepsilon$ is the turbulence eddy dissipation, i.e. the rate at which the velocity fluctuations dissipate. The continuity equation is:

$\frac{\partial \rho}{\partial t}+\frac{\partial}{\partial x_{j}}\left(\rho U_{j}\right)=0$

The momentum equation becomes:

$$
\frac{\partial\left(\rho U_{i}\right)}{\partial t}+\frac{\partial}{\partial x_{j}}\left(\rho U_{i} U_{j}\right)=\frac{\partial p^{\prime}}{\partial x_{i}}+
$$$$
+\frac{\partial}{\partial x_{j}}\left[\mu_{e f f}\left(\frac{\partial U_{i}}{\partial x_{j}}+\frac{\partial U_{j}}{\partial x_{i}}\right)\right]+S_{M}
$$

Where $S_{M}$ is the sum of body forces, $\mu_{e f f}$ is the effective viscosity accounting for turbulence, and $\mathrm{p}^{\prime}$ is the modified pressure defined as:

$p^{\prime}=p+\frac{2}{3} p \cdot k+\frac{2}{3} \mu_{e f f} \frac{\partial U_{k}}{\partial x_{k}}$

The $k-\varepsilon$, is based on the eddy viscosity concept:

$\mu_{e f f}=\mu+\mu_{t}$

Where $\mu_{t}$ is the turbulence viscosity. The $k-\varepsilon$ model assumes that the turbulence viscosity is linked to the turbulence kinetic energy and dissipation via the relation:

$\mu_{t}=C_{\mu} \rho \frac{k^{2}}{\varepsilon}$

Where $C_{\mu}$ is a constant.

The values of $k$ and $\varepsilon$ come directly from the differential transport equations for the turbulence kinetic energy and turbulence dissipation rate: 


$$
\begin{aligned}
& \frac{\partial(\rho k)}{\partial t}+\frac{\partial}{\partial x_{j}}\left(\rho U_{j} k\right)= \\
& =\frac{\partial}{\partial x_{j}}\left[\left(\mu+\frac{\mu_{t}}{\sigma_{k}}\right) \frac{\partial k}{\partial x_{j}}\right]+P_{k}-\rho \varepsilon+P_{k b}
\end{aligned}
$$

$\frac{\partial(\rho \varepsilon)}{\partial t}+\frac{\partial}{\partial x_{j}}\left(\rho U_{j} \varepsilon\right)=\frac{\partial}{\partial x_{j}}\left[\left(\mu+\frac{\mu_{t}}{\sigma_{\varepsilon}}\right) \frac{\partial \varepsilon}{\partial x_{j}}\right]+$

$+\frac{\varepsilon}{k}\left(C_{\varepsilon 1} P_{k}-C_{\varepsilon 2} \rho \varepsilon+C_{\varepsilon 1} P_{\varepsilon b}\right)$

Where, $C_{\varepsilon 1}, C_{\varepsilon 2}, \sigma_{k}$, and $\sigma_{\varepsilon}$ are constants. $P_{k b}$ and $P_{\varepsilon b}$ represent the influence of the buoyancy forces. $P_{k}$ is the turbulence production due to viscous forces (ANSYS, 2010).

\subsubsection{The RNG k- $\varepsilon$ model in ANSYS CFX}

The RNG $k-\varepsilon$ model is based on the renormalization group analysis of the Navier-Stokes equations. The transport equations for turbulence generation and dissipations are the same as those for the standard $k-\varepsilon$ model, but its constants are different: $C_{\varepsilon 2}$ and $C_{\mu}$ become the constants $C_{\varepsilon 2 R N G}$ and $C_{\mu R N G}$, and the function $C_{\varepsilon 1 R N G}$ replaces the constant $C_{\varepsilon 1}$ (ANSYS, 2010).

So, the transport equation for turbulent dissipation becomes:

$$
\begin{aligned}
& \frac{\partial(\rho \varepsilon)}{\partial t}+\frac{\partial}{\partial x_{j}}\left(\rho U_{j} \varepsilon\right)= \\
& =\frac{\partial}{\partial x_{j}}\left[\left(\mu+\frac{\mu_{t}}{\sigma_{\varepsilon R N G}}\right) \frac{\partial \varepsilon}{\partial x_{j}}\right]+ \\
& +\frac{\varepsilon}{k}\left(C_{\varepsilon 1 R N G} P_{k}-C_{\varepsilon 2 R N G} \rho \varepsilon+C_{\varepsilon 1 R N G} P_{\varepsilon b}\right)
\end{aligned}
$$

\section{Where}

$$
C_{\varepsilon 1 R N G}=1.42-f_{\eta}
$$

and

$$
f_{\eta}=\frac{\eta\left(1-\frac{\eta}{4.38}\right)}{\left(1+\beta_{R N G} \eta^{3}\right)}
$$

Where,
$\eta=\sqrt{\frac{P_{k}}{\rho C_{\mu R N G} \varepsilon}}$

and $\beta_{\mathrm{RNG}}$ is a constant of the RNG $\mathrm{k}-\varepsilon$ model.

\subsubsection{The k-omega model in ANSYS CFX}

One of the advantages of k-omega formulations is the near wall treatment for low-Reynolds number computations. The model does not involve the complex non-linear damping functions required for the k-epsilon model and is, therefore, more accurate and more robust. A low-Reynolds kepsilon model would typically require a near wall resolution of $\mathrm{y}+<0.2$, while a low Reynolds number k-omega model would require at least $\mathrm{y}^{+}<2$. In industrial flows, even $\mathrm{y}^{+}<2$ cannot be guaranteed in most applications and, for this reason, a near wall treatment was developed for the k-omega models. It allows for smooth shift from a lowReynolds number form to a wall function formulation.

The k-omega models assume that the turbulence viscosity is linked to the turbulence kinetic energy and turbulent frequency via the relation (ANSYS, 2010):

$\mu_{t}=\rho \frac{k}{\omega}$

Where $k$ is turbulence kinetic energy and $\omega$ is the turbulence frequency.

\subsubsection{The Shear Stress Transport (SST)}

The k-omega based SST model accounts for the transport of turbulent shear stress and gives highly accurate predictions of the onset (start) and the amount of flow separation under adverse pressure gradients.

The models shown previously fail to properly predict the start and amount of flow separation from smooth surfaces because they do not account for the transport of the turbulent shear stress. These results over predict the eddy-viscosity. The proper transport behavior can be obtained by a limiter to the formulation of the eddy-viscosity.

$v_{t}=\frac{a_{1} k}{\max \left(a_{1} \omega, S F_{2}\right)}$

Where, 
$v_{t}=\mu_{t} / \rho$

In Equation 13, $S$ is an invariant measure of the strain rate, and $F_{2}$ is a blending function which restricts the limiter to the wall boundary layer, and it's given by:

$F_{2}=\tanh \left(\arg _{2}^{2}\right)$

Where,

$\arg _{2}=\max \left(\frac{2 \sqrt{k}}{\beta^{\prime} \omega y}, \frac{500 v}{y^{2} \omega}\right)$

The blending functions are critical to the success of the method. Their formulation is based on the distance to the nearest surface and on the flow variables (ANSYS, 2010).

\subsection{Initial and boundary conditions}

The initial condition of the well represents a normal drilling situation, with known constant flow rate of circulating drilling fluid and without presence of gas within the well. In this case, the drilling fluid velocity $v_{l e}$ at the entrance of the well is calculated by Equation 17:

$v_{l e}=\frac{\dot{Q}_{l}}{\pi d_{i}^{2} / 4}$

Where $\dot{Q}_{l}$ is the flow of drilling fluid injected into the well, and $d_{i}^{2}$ is the diameter of the drill string.

The pressure of the formation $\left(p_{\text {formation }}\right)$ at the point where is the entrance of drilling fluid is given by Equation 18.

$p_{\text {formation }}=\operatorname{SIDPP}+\rho_{l} g D_{p}$

Where SIDPP is the shut-in drill pipe pressure; $\rho_{l}$ is the density of the drilling fluid; $g$ is the acceleration of gravity, and $D_{p}$ is the depth of the well at that point.

After a certain period of time, when a formation with pressure above of the drilling fluid pressure is reached, the gas from this formation begins to enter the well. The pressure of this porous formation was estimated to be $10 \%$ greater than that exerted by the drilling fluid at the same point also calculated by Equation 18 (Oliveira et al., 2016).

During the entry of gas into the well, the pumping fluid conditions remained unchanged compared to the previous condition. The velocity of the gas at the entrance of the well was calculated by Equation 19. In this step, the input flow of gas was determined by the equation of permanent radial flow in porous medium for compressible fluids, shown in Equation 20 (Rosa et al., 2006).

$$
\begin{aligned}
& v_{g e}=\frac{1}{\pi d_{e} H_{\text {res }}} x \\
& x \frac{2 \pi K_{\text {res }} H_{\text {res }}\left(p_{\text {fformation }}-p_{\text {bottom }}\right)}{\mu_{g} \ln \left(d_{\text {res }} / d_{e}\right)}
\end{aligned}
$$

$$
\dot{Q}_{g}=\frac{2 \pi K_{\text {res }} H_{\text {res }}\left(p_{\text {formation }}-p_{\text {bottom }}\right)}{\mu_{g} \ln \left(d_{\text {res }} / d_{e}\right)}
$$

Where $K_{\text {res }}$ and $H_{\text {res }}$ are permeability and reservoir height, respectively; ( $p_{\text {formation }}-$ $\left.p_{\text {bottom }}\right)$ is the differential pressure in the bottomhole; $\mu_{g}$ is the gas viscosity; $d_{r e s}$ and $d_{e}$ are the diameters of the reservoir and the well, respectively; and $\pi d_{e} H_{\text {res }}$ is the surface area of the gas entrance.

The gas density is calculated using Equation 21.

$\rho_{g}=\frac{\left(p_{\text {bottom }}+p_{\text {atm }}\right) M}{Z^{\prime} R T}$

Where $p_{\text {bottom }}$ and $p_{\text {atm }}$ are the pressures in the bottomhole and the atmospheric pressure, respectively, $M$ is the molecular mass of the gas, $Z^{\prime}$ is the compressibility factor, $\mathrm{R}$ is the universal gas constant, and $T$ is the temperature in the bottomhole.

The gas viscosity $\left(\mu_{g}\right)$ given in micropoise was calculated by Equation 22 which was developed by Lee et al. (1966).

$\mu_{g}=K^{\prime} \exp \left[X^{\prime} \rho_{g}^{Y^{\prime}}\right]$

Where:

$K^{\prime}=\frac{(7.77+0.063 M) T^{1,5}}{122.4+12.9 M+T}$ 
Table 4. Parameters used in simulations.

\begin{tabular}{ll}
\hline Paramaters & Valor (Unid. SI) \\
\hline Total depth of the well & $3600 \mathrm{~m}$ \\
Thickness of the water depth & $1000 \mathrm{~m}$ \\
Well diameter & $0.2032 \mathrm{~m}$ \\
Outside diameter of the drill string & $0.1219 \mathrm{~m}$ \\
Thickness of the drill string & $0.01016 \mathrm{~m}$ \\
SIDPP & $3.102610^{6} \mathrm{~Pa}$ \\
Density of the drilling fluid & $1199 \mathrm{~kg} / \mathrm{m}^{3}$ \\
Surface temperature & $300 \mathrm{~K}$ \\
Pressure on the surface & $101325 \mathrm{~Pa}$ \\
Geothermal gradient & $0.025 \mathrm{~K} / \mathrm{m}$ \\
Reservoir permeability & $9.869210^{-13} \mathrm{~m}$ \\
Reservoir height & $0.254 \mathrm{~m}$ \\
Reservoir diameter & $1000 \mathrm{~m}$ \\
Acceleration of gravity & $9.8066 \mathrm{~m} / \mathrm{s}^{2}$ \\
Pressure in the bottomhole & $4.997710^{7} \mathrm{~Pa}$ \\
Temperature in the bottomhole & $365 \mathrm{~K}$ \\
Speed of drilling fluid in the inlet & $3.9831 \mathrm{~m} / \mathrm{s}$ \\
Speed of the gas at the inlet & $0.1838 \mathrm{~m} / \mathrm{s}$ \\
\hline
\end{tabular}

Sources: Avelar (2008); Perry (1999), Reid et al. (1986).

Table 5. Points for data acquisition.

\begin{tabular}{lccc}
\hline Points / coordinates & $X(\mathrm{~cm})$ & $\mathrm{Y}(\mathrm{cm})$ & $\mathrm{Z}(\mathrm{cm})$ \\
\hline Point 1 & 9.906 & 254 & 0 \\
Point 2 & 9.906 & 1778 & 0 \\
\hline
\end{tabular}

$X^{\prime}=2.57+\frac{1914.5}{T}+0.0095 M$

$Y^{\prime}=1.11-0.04 X^{\prime}$

Where $\rho_{g}$ is the gas density, given in $\mathrm{g} / \mathrm{cm}^{3} ; T$ is the local temperature given in ${ }^{\circ} \mathrm{R}$; and $M$ is the molecular weight of the gas, given in $\mathrm{g} / \mathrm{mol} . X^{\prime}, Y^{\prime}$, and $K^{\prime}$ are Lee equation parameters.

Other parameters and initial conditions used in the simulations are summarized in Table 4.

\subsection{Data acquisition}

Several simulations were performed, for all turbulence models, and the results were analyzed in two points. The location of these points are presented in Table 5, and represented in Figure 3. The $\mathrm{X}$-axis start at the center of the well, and the $\mathrm{Y}$ axis starts at the bottomhole.

\section{RESULTS AND DISCUSSIONS}

In the present paper, were analyzed four different turbulence models: k-epsilon; RNG $k$ epsilon; k-omega; and SST, all integrated into the software. 


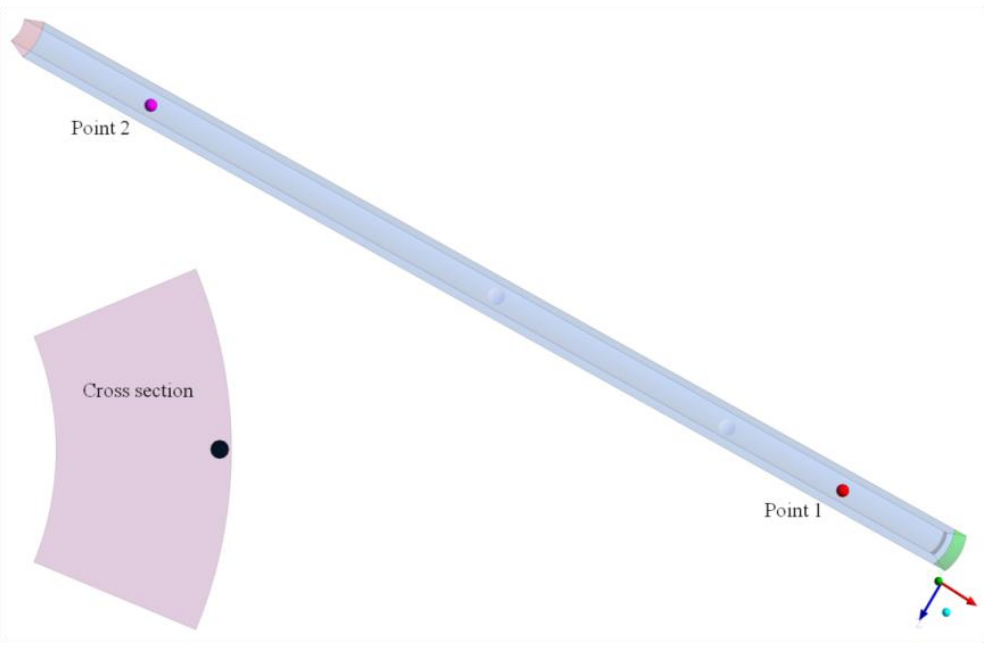

Figure 3. Data point locations.

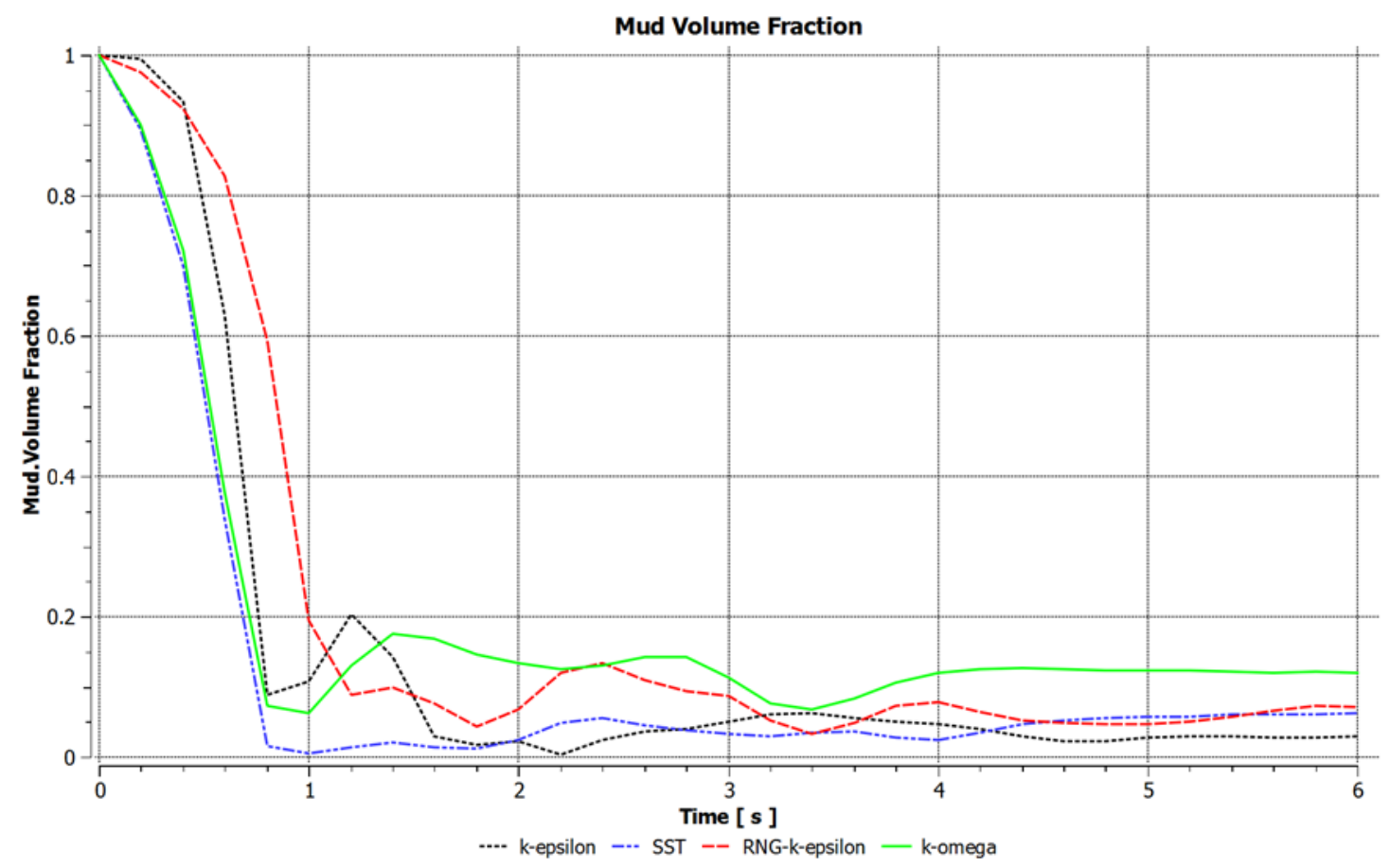

Figure 4. Power Law fluid volume fraction in the point 1.

To evaluate the behavior of each model, eight simulations were performed. The first four simulations were performed using the Power Law fluid with each model and a Bingham fluid with the last four. Table 2 shows the fluids parameters. All other settings were kept unchanged for all simulations.

Figures 4 and 5 show the mud volume fraction behavior, using the Power Law fluid for all models in points 1 and 2, respectively.
In Figure 4, in all cases during the first second after the gas invasion, the concentration of fluid falls abruptly and the mixture drilling fluid-gas is chaotic. In the next seconds, both fluids tend to reach the equilibrium, and flow almost uniformly by the end of simulation time.

Model SST shows a greater drop in the volume fraction at the beginning of the event, i.e., a greater invasion of methane in the drilling fluid, but, over the time, it stabilizes at about the same 


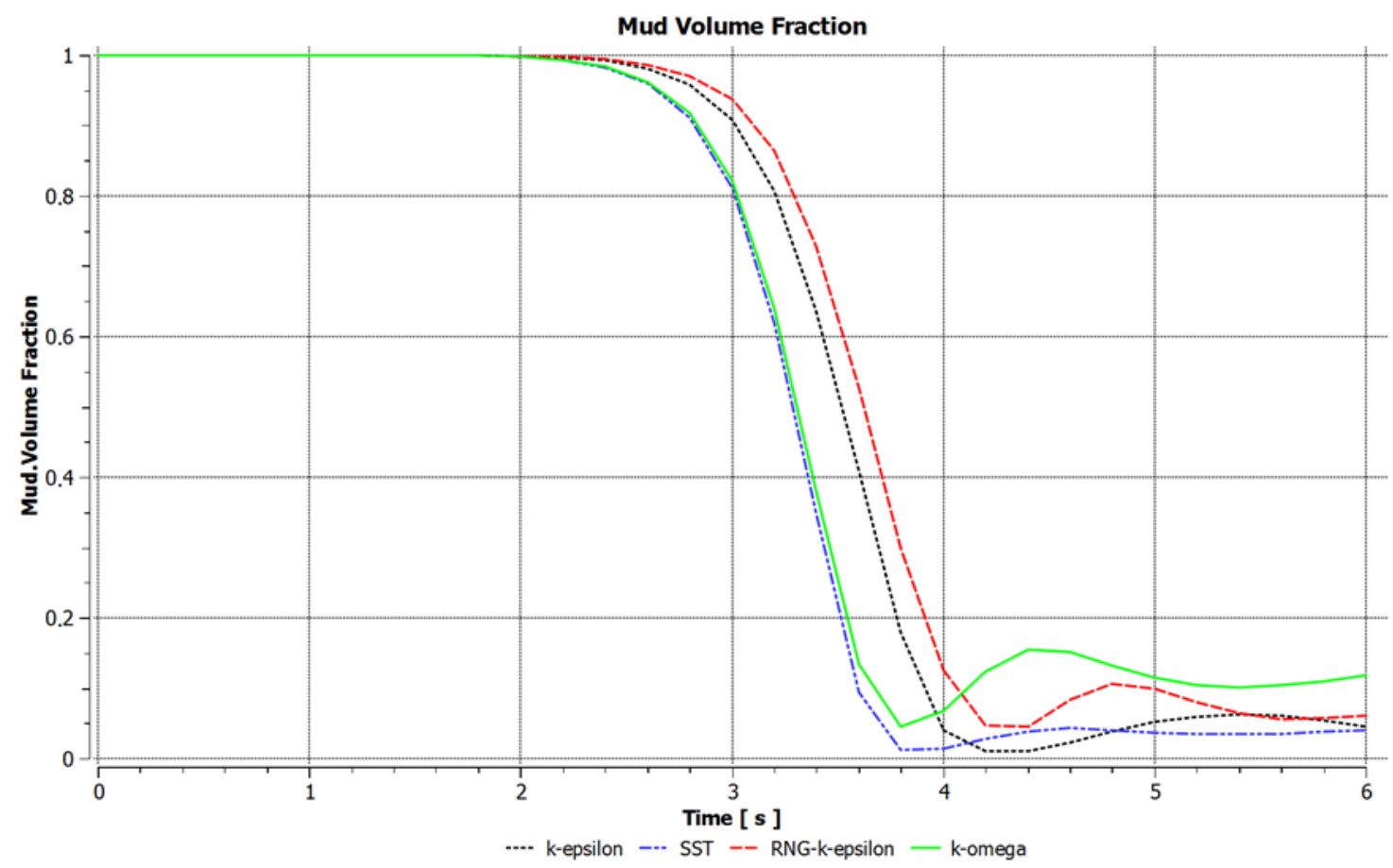

Figure 5. Power Law fluid volume fraction in the point 2.

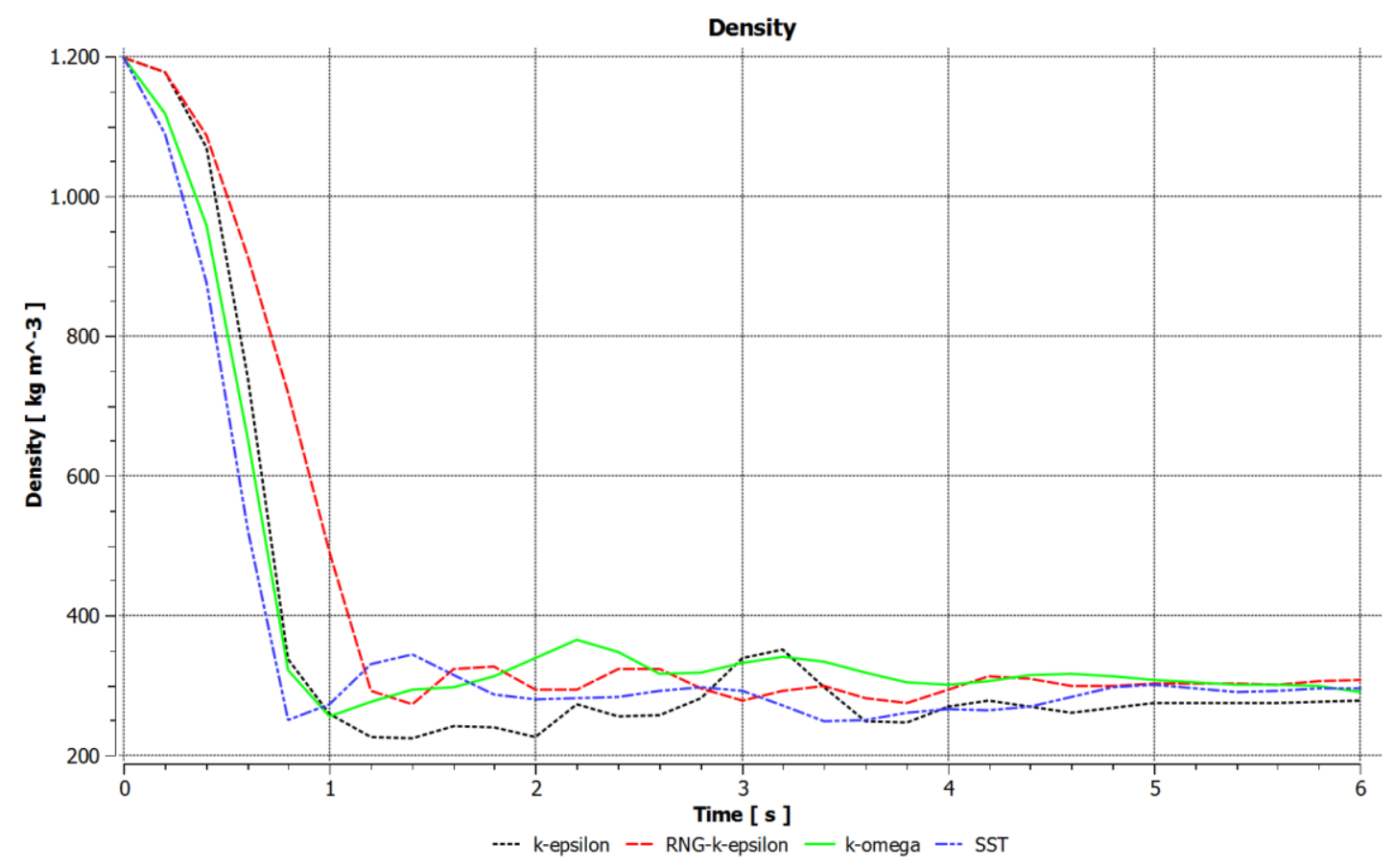

Figure 6. Density variation in the point 1.

time of the other models. Figure 5 shows the mud volume fraction in point 2.

Looking at the graphs present in Figures 4 and 5, one can note that, for both points analyzed, the concentration of drilling fluid decreases faster when using the SST model. Nonetheless, RNG k- epsilon is the model that used a slower invasion of gas.

Figures 6 and 7 show the density behavior of the mixture drilling fluid-gas, using the Bingham fluid, for all models in the same points 1 and 2, respectively. 


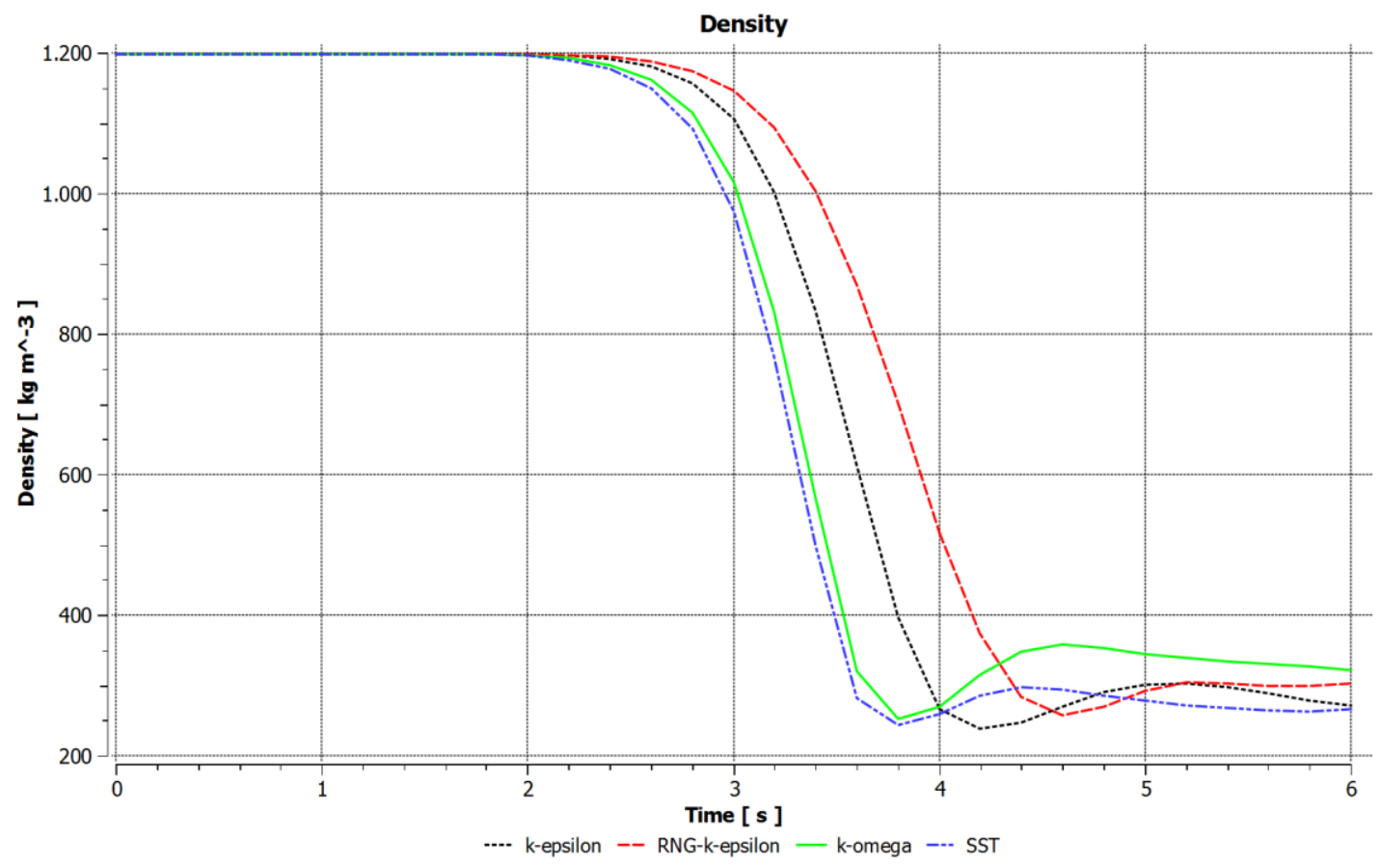

Figure 7. Density variation in point 2.

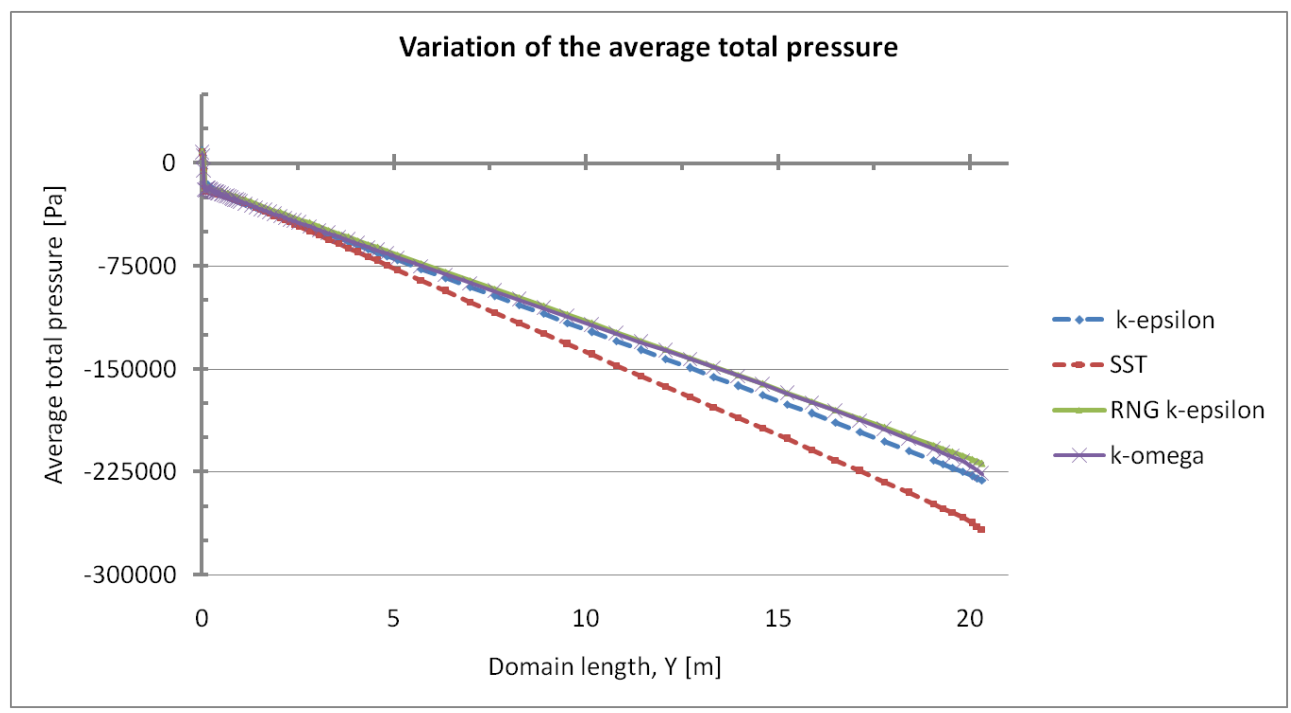

Figure 8. Variation of average total pressure in transversal sections along the domain at the final moment of the simulations.

In Figure 6 one can observe a greater drop in mixture density at the beginning, for the SST model and a slower drop for the RNG k-epsilon model, but at the end of the simulation time, all models stabilize at very close values.

In Figure 7 one can see, in point 2, a similar pattern to that shown in Figure 5, spaced slightly more.

Comparing Figures 4 to 7 , one can be observe that, for both fluids analyzed, the SST model was one that led to a more rapid invasion of the gas. The RNG k-epsilon model displayed a greater resistance to invasion, and both fluids exhibited similar behavior when using the same turbulence model.

This study also evaluated the total pressure over the area used for all turbulence models analyzed. To generate the graph shown in Figure 8 , a crosssection was taken along the length L6 (Figure 2C) 

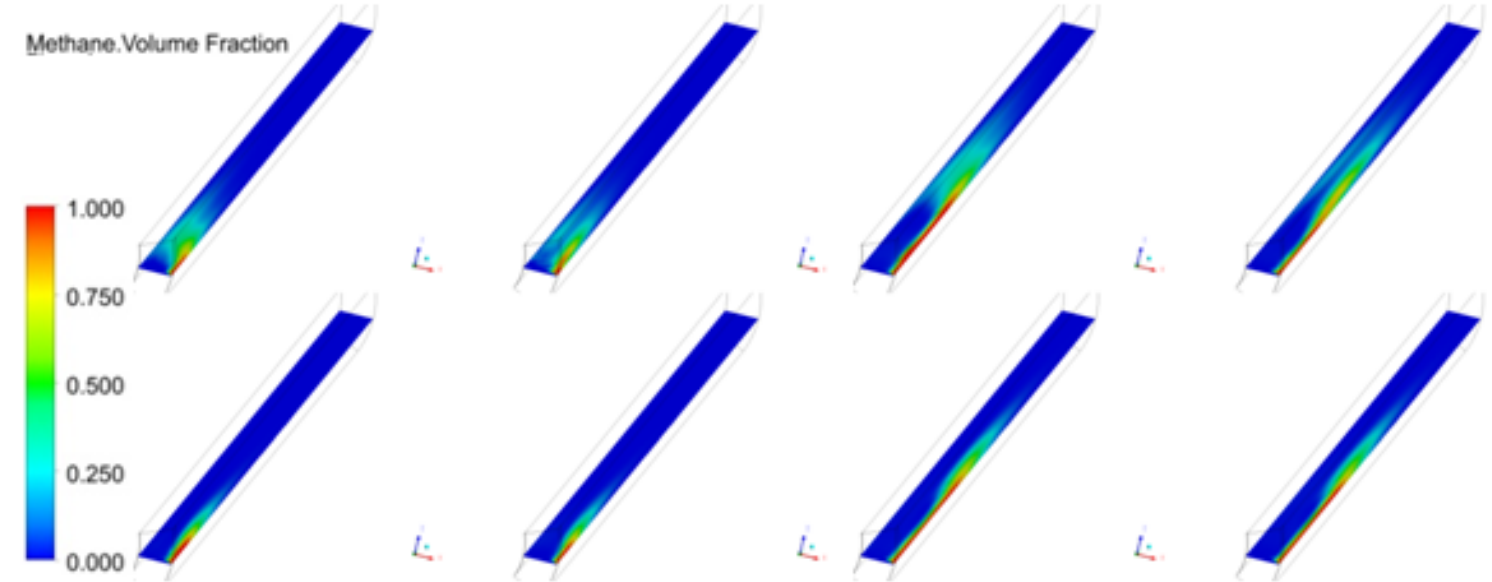

L.
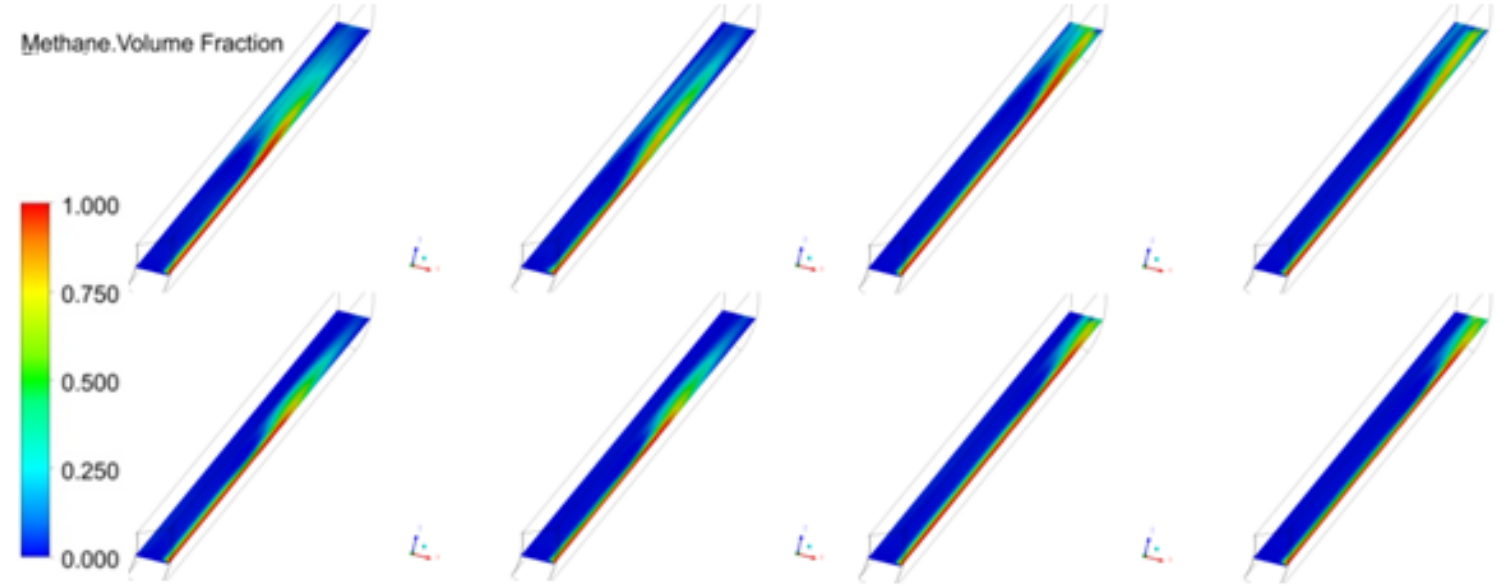

Figure 9. Progress of Methane gas invasion at selected times $(0.6 ; 1.6 ; 2.6$; and 3.6 seconds of simulation) for all four models analyzed. In each image, it was maintained the following model order: top left: k-epsilon; lower left SST; top right: RNG-k-epsilon; and lower right: k-omega).

and, in each section, the average pressure of the area of these transverse planes was taken at the final moment of the simulations. The distance between the sampling plans can be seen from the points along the graph lines. Here, the Power Law fluid was used.

According to the graph in Figure 8, one can note that using the SST model a greater pressure drop along the domain was observed. The pressure drop difference between RNG k-epsilon and SST models, after $20 \mathrm{~m}$ of the domain, was almost $50 \mathrm{kPa}$, while differences between RNG k-epsilon and k-omega models, and k-epsilon and RNG k-epsilon models, were less than $7 \mathrm{kPa}$, at the same domain length. It can also be noted that in the initial stretch, all models exhibited closer pressure drops, less than 2 $\mathrm{kPa}$, increasing the difference along the domain's length.
The following images sequence in Figure 9 shows the progress of gas invasion for all models at selected times using the Bingham fluid.

According to Figure 9, it can be seen that SST and k-omega models exhibit similar behavior regarding the front of the gas invasion. In these models, the gas flows near the wall. This is probably due to the fact that these models are able to predict the onset and amount of flow separation under adverse pressure gradients and presents, in principle, better resolutions at the walls. K-epsilon and RNG k-epsilon also present a similar behavior, but the front of gas invasion tended to invade the whole annulus. This result was expected since RNG-k-epsilon model is based on the k-epsilon model, only differentiating by redefining the constants of the model to normalize the NavierStokes equations. 


\section{CONCLUSIONS}

In this work, the authors developed and implemented a simplified kick simulator aiming at the analysis, through graphics, the dynamic behavior of some variables, such as, volume fractions of drilling fluid, total pressure, and density of the gas-liquid mixture into the well. Four turbulence models: k-epsilon, RNG k-epsilon, komega, and SST; and two drilling fluids: one Power Law fluid and one Bingham fluid were analyzed. All models were tested for each fluid.

During the analysis with Power Law fluid, it was noted that the model SST shows a greater drop of the volume fraction at the beginning of the event but, over the time, it stabilizes approximately the same way as the other models. It was also noted that in both points analyzed, the concentration of drilling fluid fell faster when using the SST model. The RNG k-epsilon model presented a slower invasion of gas.

Analysis with Bingham fluid showed a greater drop in mixture density at the beginning, for the SST model and a slower drop for the RNG k-epsilon model. At the end of the simulation time, all models stabilized at very close values.

Comparing all simulations, one can be observe that, for both fluids analyzed, the SST model was one that allowed a more rapid invasion of the gas. When using the RNG k-epsilon model, there was a greater resistance to invasion, and both fluids exhibited a similar behavior when using the same turbulence model.

This study also compared the pressure drop for all turbulence models noting that, when using the SST model, a greater pressure drop along the domain was observed. In the initial stretch, all models exhibited very closer pressure drops, less than $2 \mathrm{kPa}$, increasing the difference along the domain length.

\section{NOMENCLATURE}

\begin{tabular}{lll}
$d_{e}$ & Outer diameter of the well & $m$ \\
$d_{i}$ & Inner diameter of drill string & $m$ \\
$D_{p}$ & depth of the well & $m$ \\
$d_{\text {res }}$ & Reservoir diameter & $m$ \\
\hline
\end{tabular}

\begin{tabular}{|c|c|c|}
\hline g & acceleration of gravity & $\mathrm{m} \cdot \mathrm{s}^{-2}$ \\
\hline $\mathrm{H}_{\text {res }}$ & Reservoir height & $\mathrm{m}$ \\
\hline k & Turbulence energy & --- \\
\hline K & consistency index & $\mathrm{kg} \cdot \mathrm{m}^{-1} \mathrm{~s}^{-2} \mathrm{~s}^{\mathrm{n}}$ \\
\hline $\mathrm{K}_{\text {res }}$ & Reservoir permeability & $m^{2}$ \\
\hline M & Molecular mass of the gas & --- \\
\hline $\mathrm{n}$ & behavior index & --- \\
\hline$p_{\text {atm }}$ & Atmospheric pressure & $\mathrm{Pa}$ \\
\hline$p_{\text {formation }}$ & Formation pressure & $\mathrm{Pa}$ \\
\hline$P_{\text {bottom }}$ & Bottomhole pressure & $\mathrm{Pa}$ \\
\hline$\dot{Q}_{g}$ & Flow of gas & $\mathrm{m}^{3} \cdot \mathrm{s}^{-1}$ \\
\hline$\dot{Q}_{l}$ & Flow of drilling fluid & $\mathrm{m}^{3} \cdot \mathrm{s}^{-1}$ \\
\hline $\mathrm{R}$ & Universal gas constant & $\mathrm{m}^{2} \cdot \mathrm{s}^{-2} \cdot \mathrm{K}^{-1}$ \\
\hline SIDPP & shut-in drill pipe pressure & $\mathrm{Pa}$ \\
\hline $\mathrm{T}$ & Bottomhole temperature & $\mathrm{K}$ \\
\hline$v_{\text {ge }}$ & $\begin{array}{l}\text { Velocity of the gas in the } \\
\text { entrance }\end{array}$ & $m \cdot s^{-1}$ \\
\hline $\mathrm{v}_{\mathrm{le}}$ & $\begin{array}{l}\text { Velocity of the drilling fluid in } \\
\text { the entrance }\end{array}$ & $\mathrm{m} \cdot \mathrm{s}^{-1}$ \\
\hline$x$ & Cartesian coordinate & $\mathrm{m}$ \\
\hline Y & Cartesian coordinate & $\mathrm{m}$ \\
\hline Z & Cartesian coordinate & $\mathrm{m}$ \\
\hline$Z^{\prime}$ & Compressibility factor & --- \\
\hline Y & Shear stress rate & $s^{-1}$ \\
\hline$\mu_{\mathrm{a}}$ & Apparent viscosity & Pa.s \\
\hline$\mu_{\mathrm{g}}$ & Gas viscosity & Pa.s \\
\hline$\mu_{\mathrm{p}}$ & Plastic viscosity & Pa.s \\
\hline$\rho_{\mathrm{g}}$ & Gas density & $\mathrm{kg} \cdot \mathrm{m}^{-3}$ \\
\hline$\rho_{l}$ & density of the drilling fluid & $\mathrm{kg} \cdot \mathrm{m}^{-3}$ \\
\hline$\tau$ & Shear stress & $\mathrm{Pa}$ \\
\hline$\tau_{\mathrm{L}}$ & Yield stress & $\mathrm{Pa}$ \\
\hline$\omega$ & turbulence eddy dissipation & --- \\
\hline
\end{tabular}

\section{REFERENCES}

Ajienka, J. A.; Owolabi, O. O. Application of mass balance of kick fluid in well control. Journal of Petroleum Science and Engineering, v. 6(2), p. 161174, 1991.

http://dx.doi.org/10.1016/0920-4105(91)90035-L

ANSYS CFX-Solver Theory Guide. Release 13.0. Nov. 2010. 
Avelar, C. S. Modelagem do controle de poços por diferenças finitas. 118f. Dissertação de Mestrado. Programa de Pós-Graduação em Ciências e Engenharia do Petróleo, UNICAMP, 2008.

Grace, R.D. Blowout and well control handbook. USA: Gulf Professional Publishing, 2003.

Klein, T. S. Estudo de um novo modelo de turbulência. 222f. Dissertação de Mestrado. Programa de Pós-Graduação em Tecnologia de Processos Químicos e Bioquímicos, UFRJ, 2007.

Lee, A. L.; Gonzalez, M. H.; Eakin, B. E. The viscosity of natural gases. SPE 1340 - Journal of Petroleum Technology, p. 997-1000, 1966. http://dx.doi.org/10.2118/1340-PA

Limoeiro, C. S. Implementação de um modelo de kick para a perfuração offshore. 82f. Projeto de Graduação. Curso de Engenharia do Petróleo, UFRJ/POLI, 2011.

Martins, A. L.; Waldmann, A. T. A.; Souza, E.; Andrade, A. R. R\&D efforts to control, monitor and identify drilling fluid invasion into reservoir rocks. In: 1st International Conference on Upstream Engineering and Flow Assurance, a part of the 2012, AIChE Spring Meeting, Texas, USA, Apr/2012.

Nelson, C. Turbulence models. 2014. Available in: http://www.innovative-cfd.com/turbulencemodel.html. Accessed in July, 21st, 2014.
Nunes, J. O. L. Estudo do controle de poços em operações de perfuração em águas profundas e ultra profundas. 157f. Dissertação de Mestrado. Programa de Pós-Graduação em Ciências e Engenharia do Petróleo, UNICAMP, 2002.

Nygaard, G.; Nævdal, G. Nonlinear model predictive control scheme for stabilizing annulus pressure during oil well drilling. Journal of Process Control, v. 16(7), p. 719-732, 2006.

http://dx.doi.org/10.1016/i.jprocont.2006.01.002

Oliveira, F. F.; Sodré, C. H.; Marinho, J. L. G. Numerical investigation of non-Newtonian drilling fluids during the occurrence of a gas kick in a petroleum reservoir. Brazilian Journal of Chemical Engineering, v 33(02), p. 297-305, 2016. http://dx.doi.org/10.1590/0104-6632.20160332s20140024

PEACE Software. Some scientific and engineering data online. 2013. Available in: $<$ http://www.peacesoftware.de/einigewerte/einig ewerte_e.html>. Accessed in: Oct, 10th, 2013.

Perry, R. H. Perry's Chemical Engineers' Handbook. 7. ed. USA: McGraw-Hill, 1999.

Reid, R. C.; Prausnitz, J. M.; Poling, B. E. The Properties of Gases e Liquids. $4^{\text {th }} \mathrm{Ed}$. Singapore: Mc-Graw-Hill, 1986.

Rosa, A. J.; Carvalho, R. S.; Xavier, J. A. D. Engenharia de Reservatórios de Petróleo. Rio de Janeiro: Interciência, 2006. 832p. 